\title{
ANALYSIS OF THE SEASONAL AND REGIONAL VARIATIONS IN THE ACCIDENT HAZARD IN POLAND
}

\author{
LEON PROCHOWSKI ${ }^{1,2}$, HANNA KOCHANEK ${ }^{3}$, MIROSŁAW GIDLEWSKI ${ }^{1,3}$ \& TOMASZ PUSTY ${ }^{1}$ \\ ${ }^{1}$ Automotive Industry Institute, Poland \\ ${ }^{2}$ Military University of Technology, Poland \\ ${ }^{3}$ University of Technology and Humanities, Poland
}

\begin{abstract}
Numerical data about road accidents, collected in monthly steps, were used to build a time series. The series, covering the years 2010-2016 and 16 regions, was analysed to identify some time-dependent and regional circumstances that cause high variability in the number of accidents in annual cycles. In consideration of the nature of these data, they have been described with taking into account the trends as well as random and cyclic variations related to the annually repeating changes. In the process of clearing the time series of the trend component, a multiplicative model of seasonal variations was used. As a result, a time series was obtained, which exclusively consisted of seasonal and random variations. The time series became a basis for the carrying out of medium-term and short-term analyses, which covered seasonal fluctuations in the number of accidents. As an objective, the regional factors having an impact on the course of individual phases of these variations were sought. The like phases of the cycles were identified and then their numerical characteristics were compared with each other and referred to specific regions of Poland. The research results provide grounds for indicating the factors that generate a relation between the cycles and the territorial distribution of accidents. The knowledge of the factors that are important for the occurrence of road accidents enables the forecasting where and when seasonal actions should be taken in the field of e.g. road traffic organization, work of traffic control and road rescue services, etc. Thanks to the data analysis method adopted, the impact of seasonal variations on the course of changes in the regional accident hazard could be isolated.

Keywords: road accidents, seasonality index, annual cycles, territorial distribution of accidents.
\end{abstract}

\section{INTRODUCTION}

The downward trend in the number of accidents in Poland, observed for several recent years, is not uniform in terms of time and territorial distribution [1], [2]. Unfavourable wide seasonal fluctuations in the number of accidents were recorded in many regions (defined as voivodships, i.e. administrative province areas). An analysis of seasonal and territorial variations in accident hazard will make it possible to identify the basic features describing the nature of these variations from the point of view of their time and place.

The processes of seasonal fluctuation in the number of accidents are examined from many aspects. In most cases [3]-[6]. In a more detailed approach to the distribution of road accidents (as presented in [7]), differences between the territorial distribution of the number of accidents and the nationwide average density of accidents in Poland have also been highlighted. In [8], a relation was sought between the seasonality of variations in the number of accidents and the diverse shares of intoxicated drivers in traffic participants on the one hand and the state of road traffic safety in individual voivodships on the other hand. Research works are undertaken to analyse changes in the annual and monthly numbers of accidents in Poland as a whole and in individual voivodships, including the examination of these data against the background of other selected countries. The works of this kind were carried out e.g. by the authors of publications [8]-[10]. The importance of seasonal factors affecting the course of the process of improvement in road safety was taken into account in works reported 
in [9], [11]. However, there is a lack of analyses of changes in the accident hazard from the point of view of the time and place of occurrence of extreme seasonal variations.

The objective of this study was to isolate the basic features of seasonal variations in the numbers of road accidents in individual voivodships of Poland. The analysis was done for a time series cleared of the trend component; the time series thus prepared could be taken as a basis for medium-term and short-term analyses. Such analyses were carried out through periodic averaging of annual fluctuations in the seasonal number of accidents. The calculations were to result in determining the range of seasonal variations, extreme values, time of occurrence of such values, and rate of periodic changes in the seasonal fluctuations. The identification of detailed features of the seasonal accident hazard will enable the planning of necessary seasonal changes in the field of e.g. road traffic organization, work of traffic control and road rescue services, etc., in individual voivodships.

\section{CALCULATION OF THE MULTIPLICATIVE SEASONALITY INDEX}

The analysis was based on the numbers of accidents that occurred in consecutive months of the years 2010-2016 in 16 voivodships. The said numbers were arranged in a time series, which included the trend component as well as random and cyclic (seasonal) fluctuations related to periodically (annually) repeating changes [1], [2].

To describe the features of the time series, where seasonal fluctuations would be taken into account, a multiplicative model (with relatively constant fluctuations in the mutually corresponding phases of the cycle) was used in the form as follows [12]:

where:

$$
y_{t_{i j}}=f\left(t_{i j}\right) W_{j}+\xi_{t_{i j}}
$$

$y_{t_{i j}}$ - value of the time series data point at the instant $t_{i j}$;

$t_{i j}=m(i-1)+j ;(i=1, \ldots, N, j=1, \ldots, m)$;

$N$ - number of cycles; $m$ - number of phases in the cycle; $f$ - trend function;

$W_{j}$ - seasonality index for the $j^{\text {th }}$ phase of the cycle; $\xi_{t_{i j}}$ - random component.

The seasonality index values were determined in four stages [13]. At the first stage, an estimator of the linear regression function model was isolated, by the least squares method, in the form as below (treated then as a trend function):

$$
\hat{y}=a t+b
$$

At the second stage, the trend was eliminated from the time series:

$$
u_{t_{i j}}=\frac{y_{t_{i j}}}{\hat{y}_{t_{i j}}}
$$

Thus, $u_{t_{i j}}$ time series values were obtained, which comprised seasonal and random fluctuations. At the next stage, a "raw" seasonality index was determined for individual phases of the cycle:

$$
w_{j}^{\prime}=\frac{1}{N} \sum_{i=1}^{N} u_{t_{i j}}
$$

Finally, a corrected seasonality index was calculated for individual cycle phases:

$$
W_{j}=\frac{W_{j}^{\prime}}{\overline{W^{\prime}}} ; \quad \overline{W^{\prime}}=\frac{1}{m} \sum_{j=1}^{m} w_{j}^{\prime}
$$

For the annual cycle of seasonal changes, we have $\sum_{j=1}^{m} W_{j}=m, m=12$ months. 


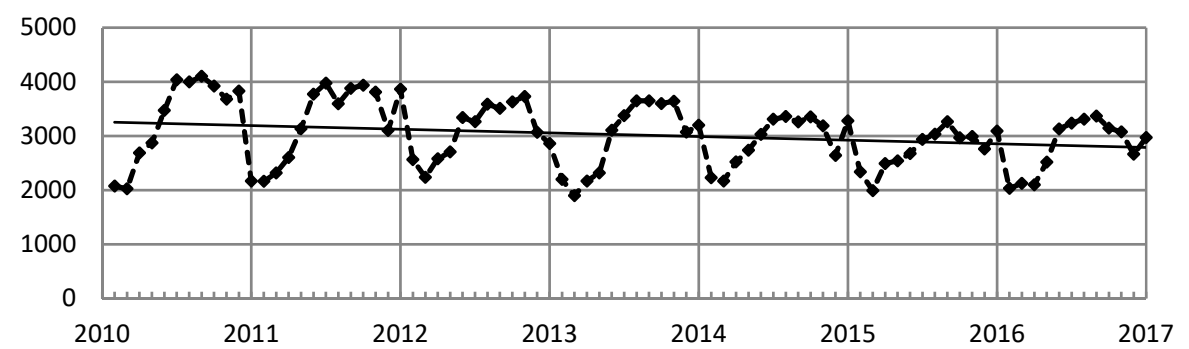

Figure 1: Variations in the number of road accidents in Poland in the years 2010-2016, with the corresponding trend line.

\section{ANALYSIS OF SEASONAL VARIATIONS IN THE ACCIDENT HAZARD}

3.1 Extreme values of the seasonality index $\mathrm{Wj}$ and time when they occurred

The above relations were used to calculate values of the seasonality index $W_{j}$ in 12 -month cycles for Poland as a whole and 16 voivodships in two short-term periods, referred to as "initial" (2010-2012) and "final" (2014-2016), and in a medium-term period (2010-2016). The calculation results have been presented in Tables 1,2, and 3. They were taken as a basis for analysing variations in the accident hazard by examining the $W_{j}$ values.

The following data were used for the analysis:

- $\quad$ extreme values of the seasonality index $W_{j}$ and time (month) when they occurred;

- range of variations in the seasonality index in the spring and autumn season;

- rate of changes in the seasonality index in the spring and autumn season, calculated in percentage terms in relation to the nationwide average values ("relative rate").

Table 1: Seasonality index values for road accidents that occurred in Poland as a whole and in individual voivodships, averaged over the period 2010-2012.

\begin{tabular}{|l|c|c|c|c|c|c|c|c|c|c|c|c|}
\hline $\begin{array}{c}\text { Years 2010-2012; } \\
\text { Region } \\
\text { (Voivodship) }\end{array}$ & Jan. & Feb. & Mar. & Apr. & May & Jun. & Jul. & Aug. & Sep. & Oct. & Nov. & Dec. \\
\cline { 2 - 12 } & $W_{1}$ & $W_{2}$ & $W_{3}$ & $W_{4}$ & $W_{5}$ & $W_{6}$ & $W_{7}$ & $W_{8}$ & $W_{9}$ & $W_{10}$ & $W_{11}$ & $W_{12}$ \\
\hline Poland & $\mathbf{0 . 7 1 0}$ & $\mathbf{0 . 6 8 6}$ & $\mathbf{0 . 8 2 0}$ & $\mathbf{0 . 9 0 6}$ & $\mathbf{1 . 0 9 8}$ & $\mathbf{1 . 1 6 9}$ & $\mathbf{1 . 1 5 6}$ & $\mathbf{1 . 1 8 6}$ & $\mathbf{1 . 1 8 3}$ & $\mathbf{1 . 1 5 2}$ & $\mathbf{1 . 0 2 6}$ & $\mathbf{0 . 9 0 7}$ \\
\hline Dolnośląskie & 0.728 & 0.773 & 0.970 & 0.998 & 1.002 & 1.199 & 1.100 & 1.026 & 1.187 & 1.158 & 1.038 & 0.820 \\
\hline Kujawsko-Pomorskie & 0.691 & 0.694 & 0.818 & 0.830 & 1.123 & 1.068 & 1.169 & 1.249 & 1.188 & 1.154 & 1.082 & 0.935 \\
\hline Lubelskie & 0.614 & 0.548 & 0.717 & 0.916 & 1.161 & 1.225 & 1.232 & 1.318 & 1.343 & 1.143 & 0.947 & 0.836 \\
\hline Lubuskie & 0.601 & 0.644 & 0.864 & 0.880 & 1.056 & 1.235 & 1.320 & 1.094 & 1.098 & 1.118 & 1.183 & 0.908 \\
\hline Lódzkie & 0.699 & 0.688 & 0.866 & 0.969 & 1.106 & 1.153 & 1.058 & 1.130 & 1.191 & 1.171 & 1.063 & 0.905 \\
\hline Małopolskie & 0.769 & 0.712 & 0.795 & 0.863 & 1.153 & 1.154 & 1.127 & 1.219 & 1.200 & 1.137 & 0.983 & 0.887 \\
\hline Mazowieckie & 0.669 & 0.726 & 0.814 & 0.910 & 1.117 & 1.167 & 1.121 & 1.150 & 1.261 & 1.203 & 0.993 & 0.867 \\
\hline Opolskie & 0.771 & 0.628 & 0.824 & 0.838 & 1.041 & 1.333 & 1.149 & 1.014 & 1.207 & 1.205 & 1.041 & 0.948 \\
\hline Podkarpackie & 0.715 & 0.695 & 0.768 & 0.898 & 1.169 & 1.153 & 1.188 & 1.225 & 1.112 & 1.168 & 0.997 & 0.913 \\
\hline Podlaskie & 0.508 & 0.619 & 0.761 & 0.849 & 1.143 & 1.058 & 1.339 & 1.419 & 1.202 & 1.163 & 1.064 & 0.875 \\
\hline Pomorskie & 0.755 & 0.665 & 0.767 & 0.851 & 1.056 & 1.259 & 1.205 & 1.249 & 1.105 & 1.117 & 1.021 & 0.950 \\
\hline Śląskie & 0.771 & 0.700 & 0.842 & 0.901 & 1.064 & 1.113 & 1.139 & 1.145 & 1.133 & 1.210 & 1.005 & 0.977 \\
\hline
\end{tabular}


Table 1: Continued.

\begin{tabular}{|l|l|l|l|l|l|l|l|l|l|l|l|l|}
\hline Świętokrzyskie & 0.677 & 0.675 & 0.763 & 0.935 & 1.155 & 1.216 & 1.130 & 1.212 & 1.241 & 1.070 & 0.962 & 0.962 \\
\hline $\begin{array}{l}\text { Warmińsko- } \\
\text { Mazurskie }\end{array}$ & 0.668 & 0.640 & 0.771 & 0.923 & 1.048 & 1.151 & 1.390 & 1.348 & 1.119 & 1.095 & 0.976 & 0.874 \\
\hline Wielkopolskie & 0.733 & 0.630 & 0.795 & 0.884 & 1.069 & 1.181 & 1.119 & 1.188 & 1.185 & 1.136 & 1.060 & 1.021 \\
\hline Zachodniopomorskie & 0.665 & 0.663 & 0.811 & 0.831 & 1.011 & 1.189 & 1.289 & 1.215 & 1.150 & 1.083 & 1.153 & 0.938 \\
\hline
\end{tabular}

Table 2: Seasonality index values for road accidents that occurred in Poland as a whole and in individual voivodships, averaged over the period 2014-2016.

\begin{tabular}{|l|c|c|c|c|c|c|c|c|c|c|c|c|}
\hline $\begin{array}{c}\text { Years 2014-2016; } \\
\begin{array}{c}\text { Region } \\
\text { (Voivodship) }\end{array}\end{array}$ & Jan. & Feb. & Mar. & Apr. & May & Jun. & Jul. & Aug. & Sep. & Oct. & Nov. & Dec. \\
\cline { 2 - 12 } & $W_{2}$ & $W_{3}$ & $W_{4}$ & $W_{5}$ & $W_{6}$ & $W_{7}$ & $W_{8}$ & $W_{9}$ & $W_{10}$ & $W_{11}$ & $W_{12}$ \\
\hline Poland & $\mathbf{0 . 7 8 6}$ & $\mathbf{0 . 7 4 7}$ & $\mathbf{0 . 8 4 5}$ & $\mathbf{0 . 9 2 4}$ & $\mathbf{1 . 0 4 4}$ & $\mathbf{1 . 1 1 9}$ & $\mathbf{1 . 1 4 3}$ & $\mathbf{1 . 1 6 3}$ & $\mathbf{1 . 1 1 2}$ & $\mathbf{1 . 0 8 4}$ & $\mathbf{0 . 9 4 3}$ & $\mathbf{1 . 0 9 1}$ \\
\hline Dolnośląskie & 0.771 & 0.791 & 0.927 & 0.895 & 1.057 & 1.127 & 1.139 & 1.125 & 1.188 & 1.039 & 0.946 & 0.995 \\
\hline Kujawsko-Pomorskie & 0.782 & 0.735 & 0.835 & 0.918 & 1.064 & 1.140 & 1.120 & 1.199 & 1.103 & 1.092 & 0.925 & 1.086 \\
\hline Lubelskie & 0.720 & 0.720 & 0.765 & 0.918 & 1.046 & 1.092 & 1.082 & 1.146 & 1.213 & 1.181 & 1.037 & 1.080 \\
\hline Lubuskie & 0.836 & 0.786 & 0.728 & 0.869 & 0.976 & 1.152 & 1.303 & 1.232 & 1.005 & 1.148 & 0.837 & 1.128 \\
\hline Lódzkie & 0.784 & 0.754 & 0.895 & 0.964 & 1.071 & 1.111 & 1.040 & 1.062 & 1.148 & 1.119 & 0.977 & 1.075 \\
\hline Małopolskie & 0.774 & 0.703 & 0.780 & 0.917 & 1.070 & 1.158 & 1.223 & 1.242 & 1.121 & 1.055 & 0.916 & 1.041 \\
\hline Mazowieckie & 0.748 & 0.729 & 0.871 & 0.924 & 1.021 & 1.135 & 1.085 & 1.095 & 1.133 & 1.113 & 0.951 & 1.195 \\
\hline Opolskie & 0.906 & 0.707 & 0.948 & 0.997 & 1.097 & 1.187 & 0.960 & 0.984 & 1.123 & 0.875 & 1.087 & 1.129 \\
\hline Podkarpackie & 0.751 & 0.826 & 0.903 & 0.901 & 1.103 & 1.041 & 1.082 & 1.256 & 1.134 & 1.097 & 0.944 & 0.961 \\
\hline Podlaskie & 0.746 & 0.670 & 0.880 & 0.967 & 1.125 & 1.139 & 1.207 & 1.262 & 1.087 & 0.978 & 0.875 & 1.063 \\
\hline Pomorskie & 0.773 & 0.708 & 0.711 & 0.924 & 1.072 & 1.197 & 1.359 & 1.243 & 1.097 & 0.964 & 0.871 & 1.083 \\
\hline Śląskie & 0.832 & 0.749 & 0.908 & 0.943 & 1.029 & 1.093 & 1.092 & 1.090 & 1.081 & 1.163 & 0.938 & 1.083 \\
\hline Świętokrzyskie & 0.835 & 0.795 & 0.774 & 0.869 & 1.055 & 1.102 & 1.180 & 1.221 & 1.057 & 1.095 & 0.952 & 1.065 \\
\hline $\begin{array}{l}\text { Warmińsko- } \\
\text { Mazurskie }\end{array}$ & 0.722 & 0.708 & 0.860 & 0.832 & 1.017 & 1.175 & 1.258 & 1.287 & 1.097 & 1.043 & 0.891 & 1.109 \\
\hline Wielkopolskie & 0.868 & 0.805 & 0.813 & 0.971 & 0.946 & 0.999 & 1.036 & 1.201 & 1.066 & 1.107 & 1.001 & 1.186 \\
\hline Zachodniopomorskie & 0.790 & 0.781 & 0.827 & 0.905 & 0.969 & 1.093 & 1.252 & 1.178 & 1.000 & 1.096 & 0.937 & 1.171 \\
\hline
\end{tabular}

Table 3: Seasonality index values for road accidents that occurred in Poland as a whole and in individual voivodships, averaged over the period 2010-2016.

\begin{tabular}{|l|c|c|c|c|c|c|c|c|c|c|c|c|}
\hline \begin{tabular}{c} 
Years 2010-2016; $\begin{array}{c}\text { Region } \\
\text { (Voivodship) }\end{array}$ \\
\cline { 2 - 12 }
\end{tabular} & $W_{1}$ & $W_{2}$ & $W_{3}$ & $W_{4}$ & $W_{5}$ & $W_{6}$ & $W_{7}$ & $W_{8}$ & $W_{9}$ & $W_{10}$ & $W_{11}$ & $W_{12}$ \\
\hline Poland & $\mathbf{0 . 7 3 1}$ & $\mathbf{0 . 6 9 3}$ & $\mathbf{0 . 8 0 5}$ & $\mathbf{0 . 8 8 5}$ & $\mathbf{1 . 0 6 1}$ & $\mathbf{1 . 1 3 8}$ & $\mathbf{1 . 1 6 0}$ & $\mathbf{1 . 1 8 5}$ & $\mathbf{1 . 1 6 4}$ & $\mathbf{1 . 1 4 6}$ & $\mathbf{1 . 0 0 5}$ & $\mathbf{1 . 0 2 7}$ \\
\hline Dolnośląskie & 0.758 & 0.767 & 0.895 & 0.900 & 0.995 & 1.129 & 1.130 & 1.095 & 1.195 & 1.155 & 1.021 & 0.970 \\
\hline $\begin{array}{l}\text { Kujawsko- } \\
\text { Pomorskie }\end{array}$ & 0.689 & 0.684 & 0.815 & 0.832 & 1.121 & 1.112 & 1.125 & 1.243 & 1.139 & 1.128 & 1.051 & 1.058 \\
\hline Lubelskie & 0.645 & 0.607 & 0.715 & 0.894 & 1.093 & 1.171 & 1.176 & 1.235 & 1.278 & 1.181 & 1.017 & 0.987 \\
\hline Lubuskie & 0.689 & 0.735 & 0.739 & 0.828 & 0.977 & 1.197 & 1.336 & 1.166 & 1.082 & 1.160 & 1.058 & 1.034 \\
\hline Lódzkie & 0.725 & 0.685 & 0.848 & 0.931 & 1.085 & 1.128 & 1.088 & 1.113 & 1.184 & 1.164 & 1.032 & 1.017 \\
\hline Małopolskie & 0.755 & 0.681 & 0.768 & 0.860 & 1.097 & 1.147 & 1.180 & 1.244 & 1.187 & 1.123 & 0.968 & 0.989 \\
\hline Mazowieckie & 0.706 & 0.700 & 0.811 & 0.895 & 1.063 & 1.145 & 1.108 & 1.124 & 1.208 & 1.188 & 1.007 & 1.044 \\
\hline Opolskie & 0.825 & 0.673 & 0.823 & 0.880 & 1.056 & 1.197 & 1.038 & 1.078 & 1.177 & 1.083 & 1.067 & 1.103 \\
\hline Podkarpackie & 0.712 & 0.736 & 0.816 & 0.871 & 1.135 & 1.086 & 1.168 & 1.232 & 1.149 & 1.161 & 0.976 & 0.958 \\
\hline Podlaskie & 0.610 & 0.610 & 0.764 & 0.874 & 1.109 & 1.127 & 1.291 & 1.353 & 1.184 & 1.106 & 1.020 & 0.952 \\
\hline
\end{tabular}


Table 3: Continued.

\begin{tabular}{|l|l|l|l|l|l|l|l|l|l|l|l|l|}
\hline Pomorskie & 0.733 & 0.663 & 0.732 & 0.869 & 1.063 & 1.223 & 1.275 & 1.278 & 1.125 & 1.062 & 0.949 & 1.028 \\
\hline Śląskie & 0.789 & 0.713 & 0.863 & 0.912 & 1.044 & 1.102 & 1.121 & 1.124 & 1.116 & 1.200 & 0.982 & 1.035 \\
\hline Świętokrzyskie & 0.723 & 0.710 & 0.745 & 0.866 & 1.076 & 1.150 & 1.173 & 1.251 & 1.175 & 1.102 & 0.971 & 1.057 \\
\hline $\begin{array}{l}\text { Warmińsko- } \\
\text { Mazurskie }\end{array}$ & 0.711 & 0.679 & 0.811 & 0.867 & 1.009 & 1.151 & 1.303 & 1.310 & 1.128 & 1.070 & 0.955 & 1.006 \\
\hline Wielkopolskie & 0.750 & 0.685 & 0.776 & 0.898 & 0.998 & 1.077 & 1.075 & 1.199 & 1.146 & 1.168 & 1.082 & 1.147 \\
\hline Zachodniopomorskie & 0.717 & 0.685 & 0.797 & 0.826 & 1.034 & 1.154 & 1.287 & 1.182 & 1.075 & 1.115 & 1.058 & 1.071 \\
\hline
\end{tabular}

The $W j$ value calculation results were averaged over three periods, i.e. initial (2010-2012), final (2014-2016), and overall (2010-2016). In the initial period (see Table 1), the maximum $W j$ values (red font) chiefly occurred in July (3 voivodships), August (5 voivodships and Poland as a whole), and September (5 voivodships), while in the final period (see Table 2), they predominantly occurred in July (3 voivodships), August ( 7 voivodships and Poland as a whole), and September (3 voivodships). In the medium-term ("overall") period (see Table 3), the maximum $W j$ values (red font) were primarily recorded in three summer months, i.e. July (2 voivodships), August ( 8 voivodships and Poland as a whole), and September (4 voivodships), similarly to the observations made in the short-term periods. Thus, in the whole period under analysis, the maximum $W_{j}$ values mostly occurred in the summer months, but the territorial distribution of the values of this index changed in the successive years. The maximum values of this index slightly declined (by about $4 \%$ ) in that time, i.e. they ranged from 1.188 to 1.419 in the initial period and from 1.148 to 1.359 in the final period.

The minimum $W_{j}$ values (blue font in Tables 1-3) occurred in the period of reduced traffic intensity. As an example: in the years 2010-2012 (see Table 1), they were reported for January (5 voivodships) and February (11 voivodships and Poland as a whole); in 2014-2016 (Table 2), the situation slightly changed and the minimum $W_{j}$ values were recorded in January (2 voivodships), February (12 voivodships and Poland as a whole), and March (2 voivodships). In 2010-2016 (Table 3), the months when the minimum $W j$ values occurred were January (3 voivodships) and February (13 voivodships and Poland as a whole). In all the periods under analysis, the minimum values of the seasonality index occurred in winter, although their distribution varied a bit. Initially, the minimum values of the seasonality index were lower by up to almost $40 \%$ than its maximum values recorded in the summer months. However, some considerable differences can also be seen. In the final period, the trend towards the occurrence of the minimum $W_{j}$ values in February grew stronger (as observed in $75 \%$ of all the voivodships). The minimum values of this index, averaged over the whole period under analysis, fell within a range from 0.607 to 0.713 , which is very narrow for the 7 -year period. This means that in the winter months, the variations in the seasonal factors rather insignificantly affect the number of road accidents. In the short-term periods, wider variations were observed: initially, these values varied from 0.508 to 0.728 and finally, they ranged from 0.670 to 0.805 , i.e. the variations were wider by $10 \%$ to $24 \%$ in comparison with those recorded in the initial period. In consequence of the changes in the extreme $W j$ index values in the years $2010-2016$, i.e. a decline by about $4 \%$ in the maximum values and a distinct growth in the minimum values, the seasonal variation in the road accident hazard was considerably reduced. This effect in combination with the marked downward trend in the number of accidents [2], is very favourable. 
3.2 Range of variations in the seasonality index in the spring and autumn season

Two-time intervals characterized by considerable changes in the seasonality index can be seen in the annual cycle of seasonal variations. In general, the boundaries between these intervals are defined by the months when the maximum and minimum values of the seasonality index were found to occur (see Tables 1-3). The extreme values predominantly occurred in August and February or in their adjacent months. These months define the time intervals, named here for the purposes of this study as:

- time of increase in the seasonality index values, most often lasting from February to June-July;

- time of decrease in the seasonality index values, most often lasting from SeptemberOctober to January-February.

Between these periods of intensive changes, a short time interval (2 to 4 months long) may be discerned in some voivodships when only small changes in the seasonality index values could be observed.

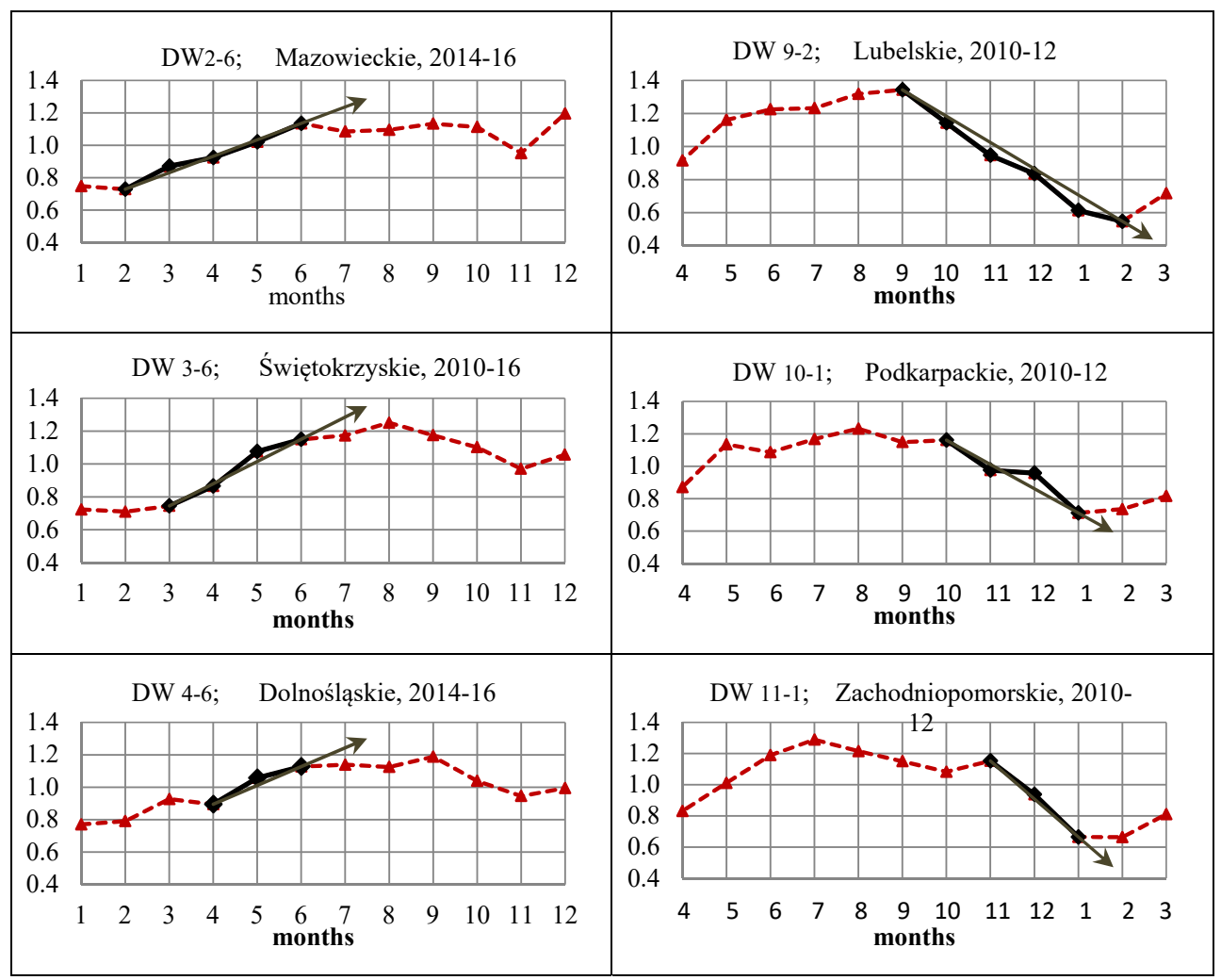

Figure 2: Examples of intensive changes in the $W j$ seasonality index values in the spring and autumn season (left and right column, respectively). 
To facilitate further description of the periods of increase and decrease in the $W j$ seasonality index values, they were called "spring growth" and "autumn drop" periods, because they begin in spring and autumn, respectively. The spring changes were calculated for the periods from February to June, from March to June, and from April to June (denoted by " $D W_{2-6}$ ", " $D W_{3-6}$ ", and " $D W_{4-6}$ ", respectively, see Fig. 2 ) and the autumn changes were calculated for the periods from September to February, from October to January, and from November to January (denoted by " $D W_{9-2}$ ", " $D W_{10-1}$ ", and " $D W_{11-1}$ ", respectively, see Fig. 2), with determining the arithmetic means of the $W j$ values for each of these periods.

The range of changes in the $W j$ values (i.e. their span) was calculated as follows:

$$
\begin{array}{ll}
D W_{m-n}=W_{n}-W_{m} & \text { for the spring growth period } \\
D W_{m-n}=W_{m}-W_{n} & \text { for the autumn drop period }
\end{array}
$$

The span values thus calculated are positive for increasing $W_{j}$ values and negative for decreasing $W_{j}$ values (Fig. 3).

Differences in the $W_{j}$ values, calculated from eqns (7) and (8), show in Fig. 3 the range and sense of changes in the average values of this index. The coloured and white bars (with coloured contours) in the graph represent the values calculated for the spring growth and autumn drop periods, respectively. In the spring period, the changes are positive, indicating growths in the $W_{j}$ values. The average $D W m-n$ values, which show the seasonal variations in the accident hazard in the years 2010-2012, fell within limits of 0.285-0.580; in the years 2014-2016, they ranged from 0.136 to 0.416 . Variations in the $\mathrm{DWm}-\mathrm{n}$ values, averaged over the whole period under analysis, were between 0.275 and 0.468 . This is quite a wide span of the seasonality index variations. It is reduced with shortening of the month intervals $m-n$ taken for the calculations according to eqns (7) and (8). In the autumn drop period, a seasonal decrease in the number of accidents was observed, which was reflected in

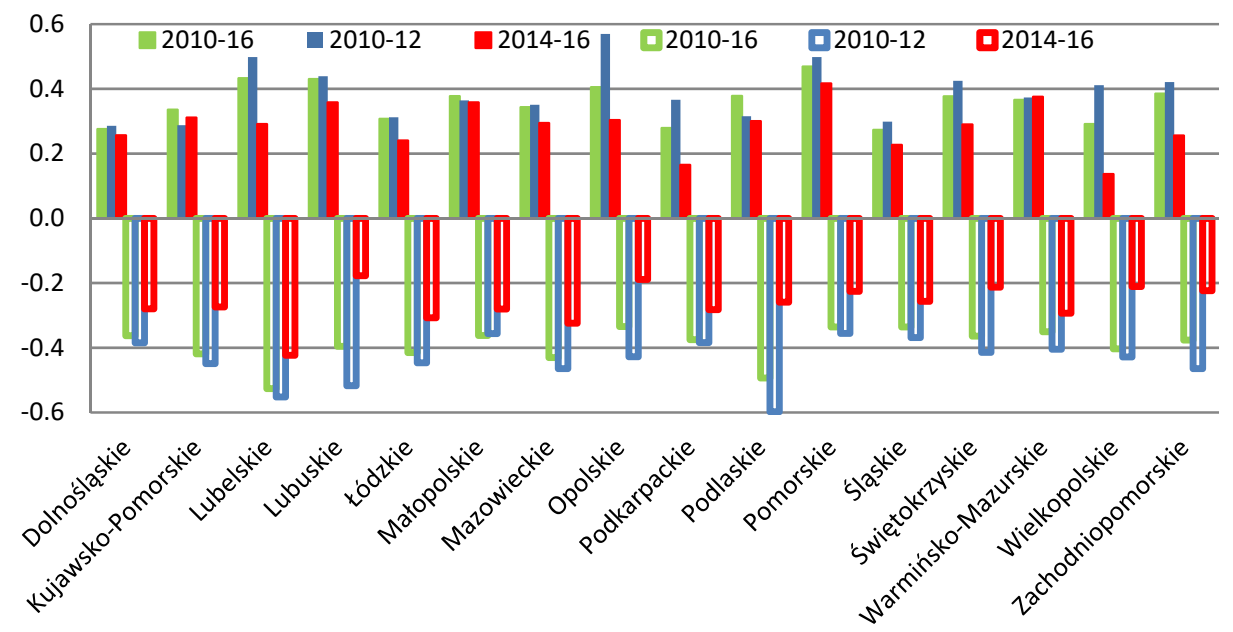

Figure 3: Summary of average DWm-n values in the short-term and medium-term periods, illustrating the range of seasonal variations in the accident hazard in the spring growth and autumn drop periods (coloured and white bars, respectively). 
a reduction in the $W j$ values (and in negative values of the calculated $D W m-n$ index). In 2010-2012, the average $D W m-n$ values ranged from -0.356 to -0.593 ; in 2014-2016, they ranged from -0.177 to -0.424 . Attention is attracted by the fact that in the final period, this span was markedly reduced in all the voivodships.

\subsection{Rate of changes in the seasonality index values}

The rate of changes in the seasonality index $W j$ in individual voivodships was calculated in percentage terms in relation to the nationwide values (as a relative rate), i.e.

$$
T W_{m-n}=\frac{D W_{m-n}-D P_{m-n}}{D P_{m-n}} 100 \%
$$

where $D W_{m-n}$ and $D P_{m-n}$ represent the ranges of variations in the $W j$ index values in the month intervals $m-n$, calculated for individual voivodships $(D W)$ and for Poland as a whole $(D P)$ from eqns (7) and (8).

The relative rate of changes calculated from eqn (9) may be either positive or negative, showing that the rate of changes in the $W j$ values for the voivodship was higher or lower, respectively, than the nationwide figure.

The calculations revealed the rate of $W j$ changes to be very diverse and depending on the selection of months taken for calculations, both in the initial and final period under analysis. The low rate of growth in these values in spring was deemed favourable. A high rate of the changes in a short time interval indicates strong but short-lasting impact of seasonal factors. As regards the average values of this relative rate, calculated from $T W_{9-2}$, $T W_{10-1}$, and $T W_{11-1}$ (cf. Fig. 4), they ranged from $-21.9 \%$ to $37.7 \%$ in the spring growth period. The growth rate definitely lower than the national average, i.e. negative values of the relative rate, may be deemed favourable. In the autumn period, the averaged values of the relative rate of changes in the $W_{j}$ values varied between $-15.0 \%$ and $35.8 \%$, i.e. within a range somewhat narrower in comparison with that observed in the spring period.

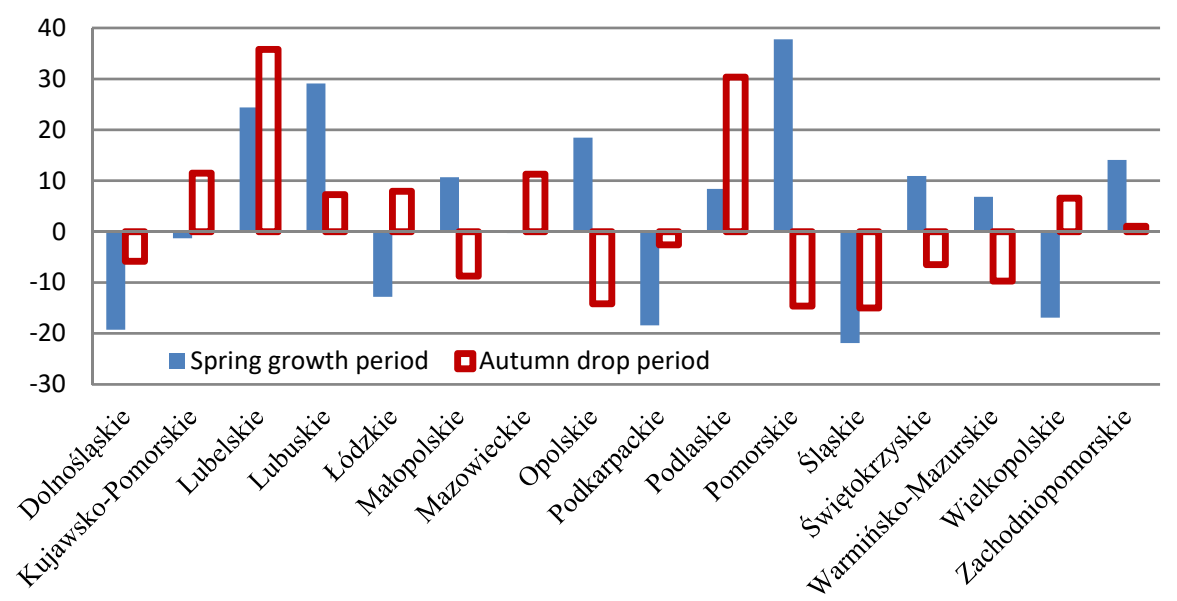

Figure 4: Summary of the $T W_{m-n}$ values, i.e. the relative rate of seasonal variations in the accident hazard in the spring growth and autumn drop periods. 


\section{TERRITORIAL DISTRIBUTION OF SEASONAL VARIATIONS IN THE ACCIDENT HAZARD}

The location in Poland of the voivodships where the observed seasonal variations in the number of accidents markedly differed from the nationwide average was also analysed. A strong impact of the factors that cause seasonal variations in the accident hazard is reflected in high values of the seasonality index $W j$ and in high rates of these changes.

In the initial period (2010-2012, see Table 1 and Fig. 5), the highest values of the maximum seasonality index Wj (MAX), occurred in Podlaskie Voivodship (1.419 in August), Warmińsko-Mazurskie Voivodship (1.390 in July), and Lubelskie Voivodship (1.343 in September). In the final period (2014-2016), for comparison, the highest values of this index (see Table 2 and Fig. 5) were reported for Pomorskie Voivodship (1.359 in July), Lubuskie Voivodship (1.303 in July), and Warmińsko-Mazurskie Voivodship (1.287 in August). The maps in Fig. 5 show that the territorial distribution of the MAX values was different in individual periods under analysis.

The voivodships where the lowest values of the minimum seasonality index $W_{j}$ (MIN) occurred in the initial period (2010-2012, see Table 1 and Fig. 6) were Podlaskie (0.508 in January), Lubelskie (0.548 in February), and Lubuskie (0.601 in January). In the final period (2014-2016), in turn, the lowest values of this index (see Table 2 and Fig. 6) were reported for Podlaskie Voivodship (0.670 in February), Małopolskie Voivodship (0.703 in February), and Opolskie Voivodship (0.707 in February). The regions where the MIN values were recorded in individual periods under analysis were not identical, either.

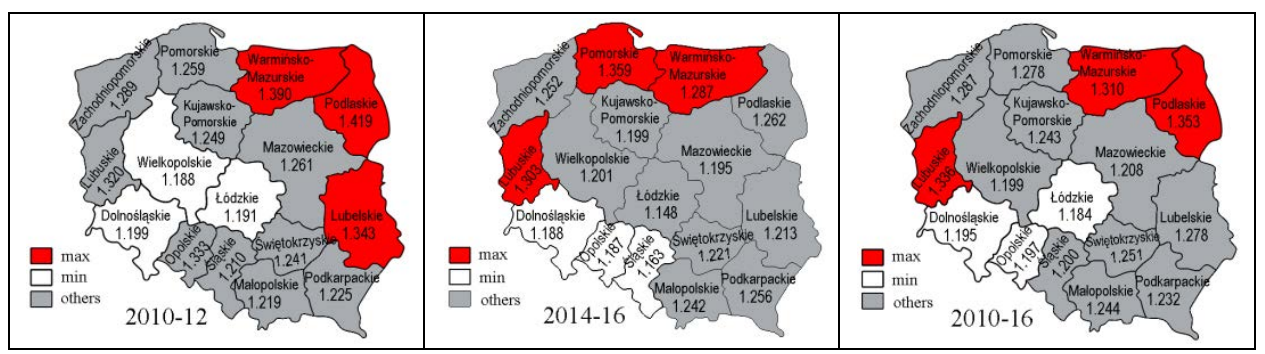

Figure 5: Voivodships where the highest and lowest values of the maximum seasonality index $W j$ (MAX) occurred; comparison between the periods 2010-2012, 20142016, and 2010-2016.

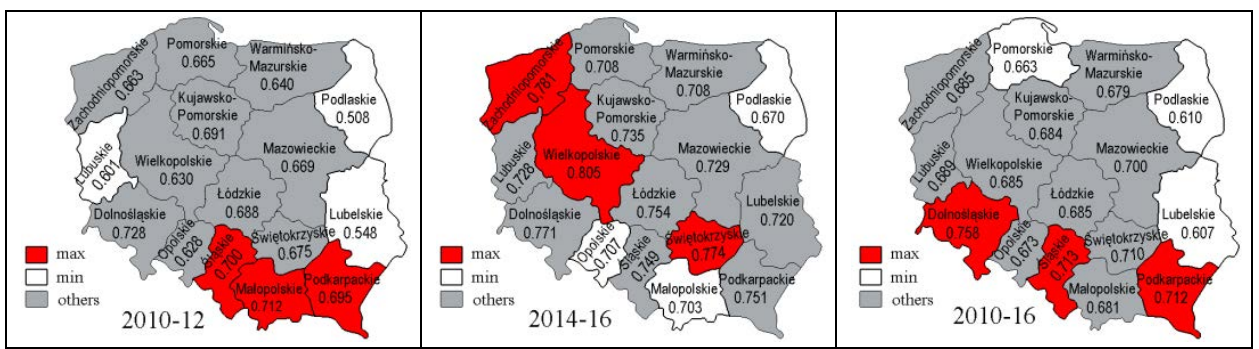

Figure 6: Voivodships where the highest and lowest values of the minimum seasonality index $W j$ (MIN) occurred; comparison between the periods 2010-2012, 20142016, and 2010-2016. 


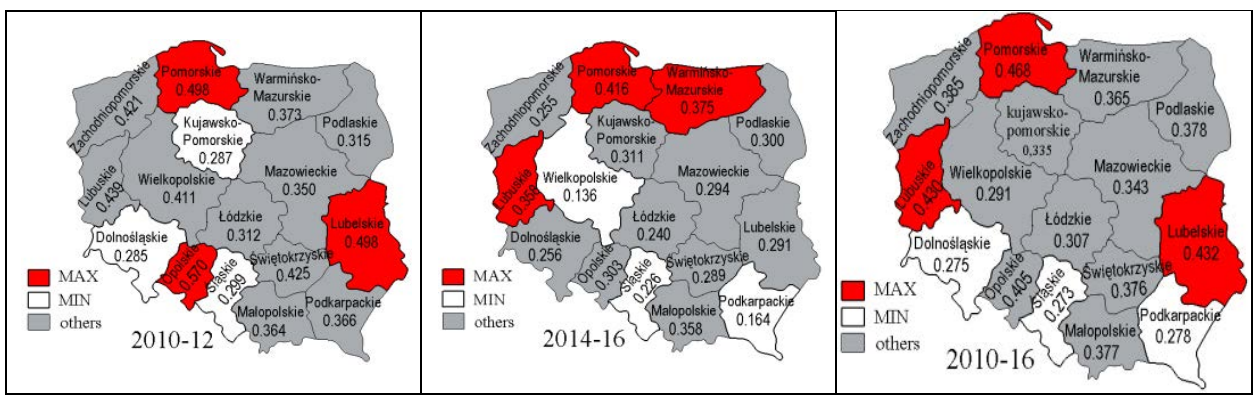

Figure 7: Voivodships where the highest and lowest average values of the $W j$ growth $\left(D W_{m-n}\right.$ values) occurred in the spring growth period.

Understanding that an increase in the $W j$ value in spring is not a desirable effect, because it means a growth in the accident hazard, we considered it noteworthy to indicate the voivodships where the biggest and smallest changes in this value occurred. This was done with taking into account the average growth value $\left(D W_{j}\right)$, calculated for three periods $\left(D W_{2-6}\right.$, $D W_{3-6}$, and $D W_{4-6}$; Fig. 2). In the initial period, the highest $D W_{j}$ values (Fig. 3 and Fig. 7) were recorded in Opolskie Voivodship (0.570), Lubelskie Voivodship (0.498), and Pomorskie Voivodship (0.498). In the final period, in turn, the highest $D W_{j}$ values occurred in spring in Pomorskie Voivodship (0.416), Warmińsko-Mazurskie Voivodship (0.375), and Lubuskie Voivodship (0.358). Hence, the widest variations in the $W_{j}$ values in spring most likely do not have any stable territorial connections, because their locations changed in the years 2010-2016 (Fig. 7).

In the initial period (see Fig. 7), the lowest $D W m-n$ values, i.e. the lowest average values of the $W_{j}$ growth, were recorded in Dolnośląskie Voivodship (0.285), Kujawsko-Pomorskie Voivodship (0.287), and Śląskie Voivodship (0.299). In 2014-2011 6, i.e. in the final period under analysis, the voivodships where the lowest values of the spring growth occurred were Wielkopolskie (0.136), Podkarpackie (0.164), and Śląskie (0.226). The territorial distribution of the areas with the smallest changes in the spring accident hazard is not stable: significant changes took place in the group of voivodships with the lowest $D W_{m-n}$ values in the whole seven-year period under analysis, too.

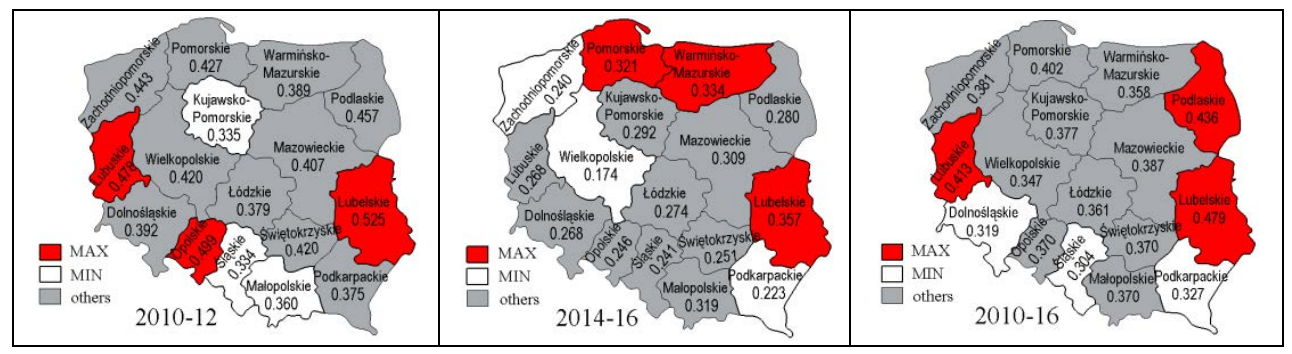

Figure 8: Voivodships where the highest (MAX) and lowest (MIN) $D W$ values occurred (changes averaged for the spring and autumn periods taken together). 
The above assessment of changes in the $W_{j}$ values in the spring growth period is not sufficient to assess the year-round level of these changes. Interest may be aroused by indicating the voivodships where the biggest seasonal changes occurred in the spring and autumn periods taken together, i.e. where the spring and autumn changes in the averaged $W j$ values were the biggest or smallest. Therefore, averaging operations were carried out, each covering three spring intervals $\left(D W_{2-6}, D W_{3-6}\right.$, and $\left.D W_{4-6}\right)$ and three autumn intervals $\left(D W_{9-2}, D W_{10-1}\right.$, and $\left.D W_{11-1}\right)$. As a result, the voivodships were identified where the biggest and smallest changes in the accident hazard took place (see Fig. 8).

\section{RECAPITULATION AND CONCLUSIONS}

The seasonal and regional variations in the accident hazard was analysed with taking into account values of the road accident seasonality index $W j$ as well as the range and rate of changes in these values. Thanks to the use of a multiplicative model, both short-term analyses (for the years 2010-2012 and 2014-2016) and medium-term analyses (for the period 20102016) could be carried out. The voivodships where extreme seasonal variations were recorded, range and time of these variations, and rate of their periodic changes were presented. As an example, the following was shown:

- course of changes in the territorial distribution of the extreme seasonality index values (minimum values in winter and maximum values in summer);

- territorial and time distribution of the minimum $W_{j}$ values in winter, gradually changing with a trend towards the occurrence of the minimum values in February (a rise from $60 \%$ to $75 \%$ of the voivodships during the 7 year period under analysis).

The minimum seasonality index values, averaged over the whole period under analysis, fell within a range of $0.607-0.713$ and the maximum values ranged from 1.188 to 1.359 . The minimum seasonality index values, recorded in winter, were lower by $40 \%$ than the maximum values of this index recorded in the summer months.

The analysis of the range of seasonal changes was based on results of the identification of the phases of growth and drop in the $W_{j}$ values (Figs 1 and 2), called "spring growth" and "autumn drop" periods, because they begin in spring and autumn, respectively. The variations in the said range, averaged over the whole period under analysis, fell within limits from 0.275 to 0.468 . This is quite a wide span of the seasonality index variations. It should be stressed that in the period 2010-2016, this span gradually decreased in all the voivodships. The occurrence of the widest variations in the $W j$ values does not have any stable territorial connections, because their locations changed in the years 2010-2016 (Fig. 5). The relative rate of changes in the $W_{j}$ values ranged from $-21.9 \%$ to $37.7 \%$ in the period of spring growth in the number of accidents. This relative rate of changes was calculated in relation to the nationwide average values. The values of the averaged relative rate of changes in the $W_{j}$ values have been presented in Fig 4. The low rate of growth in the values of this index in the spring period has been considered a favourable effect.

The calculation results show the territorial distribution and time of extreme seasonal variations in the number of road accidents and this facilitates the planning where and when seasonal actions should be taken in the field of e.g. road traffic organization, work of traffic control and road rescue services, etc., to improve road safety in specific regions of Poland. 


\section{ACKNOWLEDGEMENT}

The authors would like to express their thanks to the General Headquarter of Police in Warsaw for offering open access to the datasets that made it possible for the authors to carry out the calculations presented in this study.

\section{REFERENCES}

[1] Prochowski, L., Gidlewski, M. \& Jemioł, L., Analiza lokalnego zagrożenia wypadkowego $\mathrm{w}$ poszczególnych regionach kraju, The Archives of Automotive Engineering (in print).

[2] Prochowski, L., Gidlewski, M. \& Dąbrowski, F., Use of Regression Analysis for Comparative Evaluation of Accident Hazard in Poland, by Regions, $43^{\text {rd }}$ edition of European KONES w Krakowie, 2017.

[3] Khan, G., Qin, X. \& Noyce, D.A., Spatial analysis of weather crash patterns, Journal of Transportation Engineering, 134(5), 1 May 2008.

[4] Bergel-Hayat, R., Debbarh, M., Antoniou, C. \& Yannis, G., Explaining the road accident risk: weather effects. Accident analysis and prevention, Elsevier, 60, pp. 456465, 2013.

[5] Brijs, T., Karlis, D. \& Wets G., Studying the effect of weather conditions on daily crash counts using a discrete time series model. Accident Analysis and Prevention no. 40(3), pp. 1180-1190, 2008.

[6] Andersson, A. \& Chapman, L., The use of a temporal analogue to predict future traffic accidents and winter road conditions in Sweden, Royal Meteorological Society, Meteorological Applications, 18, pp. 125-136, 2011.

[7] Kądziołka, K., Przestrzenno - czasowa analiza nasilenia wypadków drogowych w Polsce, Electronic Scientific Journal, Contemporary Economy 6(4), 2015, Online, www.wspolczesnagospodarka.pl, Accessed on: 11 Jun. 2017.

[8] Wójcik, A., Statystyczna analiza bezpieczeństwa w ruchu drogowym w układzie województw, Studia Ekonomiczne, Zeszyty Naukowe Uniwersytetu Ekonomicznego w Katowicach Nr 220 2015, Katowice 2015.

[9] Chudy-Laskowska, K. \& Pisula, T., Prognoza liczby wypadków drogowych w Polsce, Logistyka 6; pp. 2710-2722, 2014.

[10] Mikusova, M., Joint efforts needed to prevent traffic accidents, injuries and fatalities, WIT Transactions on The Built Environment, 134, (C) 2013 WIT Press; doi:10.2495/SAFE130451.

[11] Razzaghi, A., Bahrampour, A., Baneshi, M.R. \& Zolal, F., Assessment of trend and seasonality in road accident data, International Journal of Health Policy and Management, 1(1), pp. 51-55, 2013.

[12] Dittman, P., Prognozowanie w przedsiębiorstwie. Metody i ich zastosowanie, Wolter Kluwers, Kraków 2008.

[13] Zaliaś A., Pawełek B. \& Wanat S., Prognozowanie ekonomiczne. Teoria, przykłady, zadania, Wydawnictwo Naukowe PWN, Warszawa, pp. 90-92, 2013. 